\title{
Vigor de sementes e desempenho de plantas de milho ${ }^{1}$
}

\author{
Vitor Henrique Vaz Mondo ${ }^{2 *}$, Silvio Moure Cicero², Durval Dourado-Neto², \\ Túlio Lourenço Pupim², Marcos Altomani Neves Dias ${ }^{2}$
}

\begin{abstract}
RESUMO - Estudou-se os efeitos da utilização de lotes constituídos por sementes de milho de alto ou de baixo vigor, bem como a mistura desses em diferentes proporções, simulando-se o uso de lotes de sementes homogêneos e heterogêneos quanto ao vigor das sementes, sobre o crescimento inicial e produtividade das plantas. Observou-se que plantas originadas de sementes menos vigorosas foram inferiores às originadas de sementes mais vigorosas quanto ao crescimento inicial e, para os componentes de produção, as provenientes de sementes menos vigorosas não foram inferiores nas distribuições onde houve $100 \%$ de um tipo de semente, porém, foram inferiores quanto acúmulo de massa de matéria seca, número de grãos por fileira e produtividade de grãos nas demais distribuições. Assim, vigor de sementes está diretamente relacionado ao crescimento inicial das plantas; porém, seus efeitos não persistem até o final do ciclo da cultura quando há o uso de lotes homogêneos quanto ao vigor das sementes. O uso de lotes heterogêneos resulta em maior competição intraespecífica proporcionando menor capacidade competitiva às plantas provenientes de sementes de menos vigorosas, sendo estas dominadas pelas provenientes de sementes de alto vigor, refletindo negativamente em produção por planta.
\end{abstract}

Termos para indexação: competição intra-específica, potencial fisiológico, plantas dominadas, Zea mays L.

\section{Maize seed vigor and plant performance}

\begin{abstract}
The objective of this study was to evaluate the effects of using maize seed lots constitued of high and low vigor seeds, as well as mixtures of different proportions, on plant growth and yield. Plants from high vigor seeds showed higher initial growth than those from low vigor seeds, independently of seed distribution and position in the seeding row. Comparing the yield components between plants arising from high and low vigor seeds, when the percentages of one type of seed were $100 \%$ (homogeneous lots), results were similar, but plants from low vigor seeds had inferior results on other seed distributions (heterogeneous lots). Seed vigor is directly related to initial plant growth in maize but the effects do not continue until harvest when using seed lots with homogeneous vigor. However, the use of seed lots with heterogeneous vigor results in more intra-specific competition and a lower competitive capacity for plants originating from low vigor seeds, resulting in dominated plants which grow and yield less.
\end{abstract}

Index terms: intra-specific competition, seed vigor, dominated plants, Zea mays L.

\section{Introdução}

O potencial fisiológico de sementes ainda encontra-se como o principal foco de atenção dos tecnologistas de sementes, sendo representado pela germinação e pelo vigor das sementes, determinando a capacidade da semente em estabelecer uma plântula normal. De modo geral, segundo Marcos-Filho (2005), as manifestações do baixo potencial fisiológico de lotes de sementes podem ser atribuídas à menor velocidade de germinação, maior sensibilidade das sementes e plântulas a estresses durante esse processo e plantas com crescimento vagaroso, reduzido, desuniforme e com menor desenvolvimento radicular. Essa

\footnotetext{
${ }^{1}$ Submetido em 02/04/2011. Aceito para publicação em 27/06/2011.

${ }^{2}$ Departamento de Produção Vegetal, USP/ESALQ, Caixa Postal 09, 13418-900 - Piracicaba, SP, Brasil.

*Autor para correspondência <vhvmondo@yahoo.com.br>
} 
menor velocidade de emergência deve-se ao fato de que sementes de baixo vigor, antes de dar início ao crescimento do eixo embrionário demandarem tempo para a restauração de organelas e tecidos danificados (Villiers, 1973).

Schuch et al. (2000) desenvolveram trabalho com a cultura da aveia preta no sentido de estudar o efeito do vigor das sementes no desenvolvimento de plantas, constatando que sementes de baixo vigor podem provocar reduções na velocidade de emergência de plântulas, no tamanho inicial de plantas, na área foliar, nas taxas de crescimento das plantas e no acúmulo de massa de matéria seca. Esses efeitos podem, ainda, afetar além do estabelecimento da cultura, o seu desempenho ao longo do ciclo, bem como a produtividade final. TeKrony et al. (1989) afirmaram que o vigor das sementes pode afetar o crescimento inicial das culturas, mas o efeito tende a desaparecer no final do ciclo, o que foi constatado também por Schuch et al. (2000) em aveia-preta. Assim, a influência do vigor das sementes sobre a emergência das plântulas em campo, o estabelecimento do estande e o desenvolvimento inicial das plantas é um consenso tanto para a comunidade científica quanto para o setor produtivo, especialmente sob condições menos favoráveis de ambiente (Marcos-Filho, 2005).

Quando o estudo é conduzido dentro de uma população de plantas, esse passa a ser diferente da análise de plantas de forma isolada, onde as plantas estão livres do efeito de competição (Almeida e Mundstock, 2001a). De acordo com Harper (1977) um indivíduo em uma população sofre efeitos de restrição sobre a taxa de crescimento em função da presença e arranjo dos vizinhos na população de plantas. Os efeitos da competição entre plantas acontecem tanto quando as plantas estão em maior população ou quando são dominadas por plantas vizinhas cujas plântulas emergiram mais rapidamente (MerottoJúnior et al., 1999), como por exemplo, em função do vigor das sementes. Nessa situação a desuniformidade na velocidade de emergência afetará o desenvolvimento do dossel da cultura, sendo que plântulas que emergem primeiro sombrearão as plântulas com emergência mais tardia (Pommel et al., 2002). Além disso, as plântulas com emergência atrasada podem apresentar menor crescimento da parte aérea e do sistema radicular, resultando em menor capacidade de competição por água, luz e nutrientes (Merotto-Júnior et al., 1999).

$\mathrm{O}$ uso de lotes de sementes heterogêneos quanto ao vigor das sementes pode promover desuniformidade na emergência de plântulas e, também, no crescimento inicial das plantas. Dessa forma, as plântulas que emergem primeiro e obtêm maior crescimento de parte aérea afetarão a intensidade e composição de luz incidente sobre as plantas com menor crescimento na população vegetal, consequentemente, podendo refletir no crescimento e na produtividade final individual dessas plantas. Kolchinski et al., (2005), avaliando o crescimento individual de plantas em populações de plantas de soja, verificaram que as plantas provenientes de sementes de alto vigor apresentaram maior produtividade de grãos dentro das populações, no entanto, não apresentaram dominância sobre as plantas originadas de sementes de vigor mais baixo adjacentes na linha de semeadura. Resultados semelhantes foram encontrados por Melo et al., (2006b) e Mielezrski et al., (2008), em trabalhos com sementes de arroz, mostrando que plantas originadas de sementes de alto vigor apresentaram produtividade superior às plantas originadas de sementes de vigor mais baixo.

Além disso, pode-se dizer que o aumento da produtividade final de grãos de milho está diretamente relacionado à maximização da exploração do ambiente, que acontece de forma mais efetiva quando existe uniformidade entre plantas, proporcionando baixa competição intra-específica, principalmente na cultura de milho, que é uma das espécies de gramíneas mais sensíveis à esse tipo de competição (Maddonni e Otegui, 2006).

Dessa forma, objetivou-se com esta pesquisa, estudar os efeitos do uso de lotes constituídos por sementes de milho de alto ou de vigor mais baixo, bem como de lotes resultantes da mistura desses em diferentes proporções, simulando-se o uso de lotes de sementes homogêneos e heterogêneos quanto ao vigor das sementes, sobre o crescimento inicial e produção das plantas.

\section{Material e Métodos}

A pesquisa foi desenvolvida durante as safras de 2006 e 2007 em área do Departamento de Produção Vegetal da Universidade de São Paulo(USP/ESALQ), em Piracicaba, SP. Utilizou-se parcelas com três linhas de $11 \mathrm{~m}$, e espaçamento de $0,7 \mathrm{~m}$, com área útil para avaliação, $10 \mathrm{~m}$ da linha central. O solo da localidade é Nitossolo Vermelho eutrófico (Embrapa, 2006) com 24 g.dm ${ }^{-3}$ de matéria orgânica e pH de 4,9 , sendo as parcelas adubadas na semeadura com $32 \mathrm{~kg} \cdot \mathrm{ha}^{-1}$ de $\mathrm{N}, 112 \mathrm{~kg} \cdot \mathrm{ha}^{-1}$ de $\mathrm{P}_{2} \mathrm{O}_{5}$ e $64 \mathrm{~kg} \cdot \mathrm{ha}^{-1}$ de $\mathrm{K}_{2} \mathrm{O}$, em cobertura com $90 \mathrm{~kg} \cdot \mathrm{ha}^{-1} \mathrm{~N}$ e, mantidas livres de plantas daninhas, pragas e doenças durante todo o ciclo da cultura. Durante o $1^{\circ}$ ano a área foi irrigada, propiciando o desenvolvimento adequado da cultura. No $2^{\circ}$ ano, a irrigação foi realizada apenas para permitir a emergência adequada das plântulas e obtenção do estande de plantas almejado. Dessa forma, foram caracterizadas duas condições de competição intra-específica, uma minimizada (irrigada) e outra maximizada (não irrigada).

Foram utilizadas, para cada ano, sementes certificadas de milho provenientes de dois lotes de mesma peneira, do 
híbrido DOW 8480, devidamente caracterizados, por meio de testes fisiológicos (Tabela 1). As parcelas foram constituídas por diferentes distribuições de sementes de alto vigor e de baixo vigor ao longo da linha de semeadura, simulando o uso de lotes de sementes homogêneos e heterogêneos quanto ao vigor das sementes. As distribuições foram as seguintes: 1) todas as sementes de alto vigor $[1 \mathrm{~A}: 1 \mathrm{~A}(100 \% \mathrm{~A})]$; 2$)$ três sementes de alto vigor seguidas por uma de baixo vigor [3A:1b $(75 \% \mathrm{~A})]$; 3$)$ duas sementes de alto vigor seguidas por uma de baixo vigor $[2 \mathrm{~A}: 1 \mathrm{~b}$ $(67 \% \mathrm{~A})]$; 4) uma semente de alto vigor seguida por uma de baixo vigor [1A:1b $(50 \% \mathrm{~A})]$; 5) uma semente de alto vigor seguida por duas sementes de baixo vigor [1A:2b (33\% A)]; 6) uma semente de alto vigor seguida por três sementes de baixo vigor [1 $\mathrm{A}: 3 \mathrm{~b}$ $(25 \% \mathrm{~A})]$; 7$)$ todas as sementes de baixo vigor $[1 \mathrm{~b}: 1 \mathrm{~b}(100 \% \mathrm{~b})]$.

Tabela 1. Caracterização do potencial fisiológico das sementes de milho utilizadas nos dois anos experimentais: germinação (G; \%); envelhecimento acelerado (EA; \%); emergência de plântulas em campo (EC; \%); índice de velocidade de emergência (IVE); condutividade elétrica (CE; $\left.\mu \mathrm{mhos} \cdot \mathrm{cm}^{-1} \cdot \mathrm{g}^{-1}\right)$.

\begin{tabular}{ccccccc}
\hline \multirow{2}{*}{ Avaliação } & \multicolumn{2}{c}{$1^{\mathrm{o}}$ ano } & \multirow{2}{*}{ CV $(\%)$} & \multicolumn{2}{c}{$2^{\mathrm{o}}$ ano } & \multirow{2}{*}{ CV (\%) } \\
\cline { 2 - 3 } & Lote 1 & Lote 2 & & Lote 1 & Lote 2 & \\
\hline G & $98^{\text {ns }}$ & 95 & 1,93 & $100^{\text {ns }}$ & 98 & 2,45 \\
EA & $95^{\text {ns }}$ & 88 & 6,74 & $98 \mathrm{a}$ & $91 \mathrm{~b}$ & 0,61 \\
EC & $96 \mathrm{a}^{*}$ & $92 \mathrm{~b}$ & 1,55 & $98^{\text {ns }}$ & 96 & 2,39 \\
IVE & $13,85 \mathrm{a}$ & $12,73 \mathrm{~b}$ & 3,50 & $15,96 \mathrm{a}$ & $14,77 \mathrm{~b}$ & 2,85 \\
$\mathrm{CE}$ & $20,95^{\text {ns }}$ & 21,35 & 4,13 & $17,82 \mathrm{a}$ & $23,77 \mathrm{~b}$ & 5,97 \\
\hline
\end{tabular}

*Para cada ano experimental, as médias seguidas por letras iguais na linha não diferem entre si pelo teste Scott-Knott, com 5\% de significância. ns Não significativo pelo teste F, com 5\% de significância. CV: coeficiente de variação. Métodos utilizados G: Brasil, 2009; EA e CE: Mondo e Cicero, 2005; EC: Fessel et al., 2000; IVE: Maguire, 1962).

A semeadura foi realizada em sulcos, de acordo com as proporções de sementes especificadas anteriormente, utilizando-se semeadora manual com limitador de profundidade, regulado para $0,05 \mathrm{~m}$. Em função da possível variação no potencial fisiológico entre as sementes do mesmo lote e para se obter plântulas mais representativas dos lotes de alto e de baixo vigor, foram semeadas três sementes por cova para as posições de alto vigor e quatro sementes por cova para as posições de baixo vigor, sendo realizado, posteriormente, desbaste deixando, no caso da posição de sementes de alto vigor, a plântula com emergência mais rápida e, para as posições de sementes de baixo vigor, a plântula de emergência mais tardia, obtendo-se população final de 71.429 plantas.ha ${ }^{-1}$. As covas com sementes de alto vigor foram identificadas no ato da semeadura com estacas para permitir a realização das determinações experimentais durante o ciclo da cultura.

Quanto às avaliações, todas foram realizadas em quatro plantas de cada nível de vigor e posição de semeadura. Os estádios fenológicos da cultura foram acompanhados de acordo com o procedimento citado por Fancelli e DouradoNeto (2000), tendo como referência a distribuição com $100 \%$ de plantas originadas de sementes de alto vigor.
Para análise do crescimento inicial foram mensurados altura de plantas, diâmetro de colmo e índice de área foliar nos estádio fenológicos de quatro e oito folhas. A altura das plantas foi determinada por meio da mensuração do comprimento desde o nível do solo até o ápice da planta, com o limbo foliar distendido, baseando em métodos descritos por Melo et al. (2006a), juntamente com a determinação do diâmetro de colmo, que foi mensurado na base da planta, com o auxílio de um paquímetro. $\mathrm{O}$ índice de área foliar foi calculado pela razão entre a área foliar total de uma planta (AF) e a área de solo por ela ocupada, seguindo métodos descritos por Silva et al. (1999). Para tanto, a área foliar total (AF) foi estimada pela soma da área foliar de cada folha completamente aberta, calculada aplicandose a equação $A F=0,75(C . L)$, onde C e L representam, respectivamente, comprimento e largura média, em metros, de cada folha (Montgomery, 1911).

$\mathrm{Na}$ colheita foram realizadas avaliações do acúmulo de massa de matéria seca da parte áerea, massa de mil grãos, número de grãos por fileira, número de fileiras por espiga e produtividade de grãos. Para a determinação do acúmulo de massa de matéria seca da parte aérea, as plantas foram coletadas inteiras, picadas e colocadas dentro de sacos de 
papel e, em seguida, levados à estufa com circulação de ar, regulada a $65{ }^{\circ} \mathrm{C}$, deixando-as até atingir massa constante; na sequência foi utilizada uma balança analítica, com sensibilidade de $0,01 \mathrm{~g}$ para a pesagem do material. Ainda, a esse valor foi somada a massa de matéria seca total da espiga e dos grãos de cada planta. Para o restante das avaliações foram colhidas as espigas das plantas que foram avaliadas individualmente, sendo as espigas secadas ao sol para redução do teor de água. Na sequência, foi avaliado o número de fileiras por espiga e, posteriormente, estas debulhadas manualmente. Após isso, todos os grãos de cada espiga foram contados e pesados em balança analítica, com sensibilidade de $0,01 \mathrm{~g}$, e os valores corrigidos para $13 \%$ de teor de água. A massa de mil grãos foi determinada a partir da separação de subamostra de 1000 grãos das plantas colhidas, seguindo procedimentos descritos nas Regras para Análise de Sementes (Brasil, 2009), assim como as determinações do teor de água dos grãos, estas realizadas pelo método de estufa a $105 \pm 3{ }^{\circ} \mathrm{C}$ durante 24 horas.

Para a análise estatística aplicou-se teste $\mathrm{F}$ para a análise da variância e, na ocorrência de efeitos significativos, as médias foram agrupadas pelo teste de Scott-Knott (Scott e Knott, 1974), com 5\% de significância.

\section{Resultados e Discussão}

\section{Crescimento inicial de plantas}

Com os resultados obtidos para as variáveis altura de planta (Figura 1), diâmetro de colmo (Figura 2) e índice de área foliar (Figura 3), foi possível identificar o efeito do vigor das sementes no crescimento inicial das plantas. Esses resultados, de forma geral, estratificaram as plantas originadas de sementes de alto vigor das originadas de sementes de baixo vigor. Assim, tanto nas distribuições homogêneas quanto nas heterogêneas quanto ao vigor das sementes, as plantas originadas de sementes de alto vigor foram superiores às originadas de sementes de baixo vigor. Esse efeito no crescimento inicial das plantas, visto como um impulso ao crescimento era esperado, baseando-se em trabalhos que vem sendo realizados comparando-se o efeito do vigor das sementes sobre o crescimento inicial de plantas (TeKrony et al., 1989; Schuch et al., 2000; Kolchinski et al., 2006).

As diferenças em altura de plantas puderam ser observadas em dois estádios fenológicos diferentes. Para o $1^{\circ}$ ano tanto para o estádio de quatro folhas (Figura $1 \mathrm{~A}$ ) quanto para o estádio de oito folhas (Figura 1B) pôde-se observar que as plantas provenientes de sementes de alto vigor, com exceção para a distribuição cinco, foram superiores, comparadas a todas as plantas provenientes de sementes de baixo vigor. No $2^{\circ}$ ano, as diferenças entre tratamentos foram semelhantes, sendo que nas duas avaliações, com quatro folhas (Figura 1C) e oito folhas (Figura 1D), as plantas provenientes de sementes de alto vigor foram superiores às plantas provenientes de sementes de baixo vigor dentro de cada distribuição, independentemente da distribuição de semente. Nesse contexto, Pommel et al. (2002) descreveram que plantas emergidas tardiamente e rodeadas por plantas emersas previamente devem mostrar em algum momento o atraso no crescimento foliar e crescimento em altura de plantas, o que foi realmente constatado no presente trabalho para essa variável.

De maneira semelhante, para a variável diâmetro de colmo (Figura 2) foi possível identificar dois grupos de plantas, um composto por plantas provenientes de sementes de alto vigor e um grupo composto por plantas provenientes de sementes de baixo vigor, este segundo com crescimento inferior ao primeiro, tanto para as avaliações no estádio fenológico de quatro folhas (Figuras 2A e 2C) quanto no estádio fenológico de oito folhas (Figuras 2B e 2D). Vale ressaltar que as diferenças de altura de plantas e de diâmetro de colmo foram observadas tanto nas distribuições com sementes de diferentes níveis de vigor, condições consideradas heterogêneas, quanto nas distribuições com apenas sementes de alto vigor ou de baixo vigor, consideradas homogêneas. Isso demonstra que até o estádio fenológico de oito folhas o efeito da competição intra-específica entre plantas ainda não pode ser observado, sendo as diferenças de crescimento inicial relacionadas diretamente à qualidade das sementes.

Para a variável índice de área foliar (Figura 3), foi possível observar a superioridade de crescimento das plantas provenientes de sementes de alto vigor perante as de baixo vigor, tanto no estádio fenológico de quatro folhas (Figuras 3A e 3C) quanto no de oito folhas (Figuras 3B e 3D). Esses resultados foram similares aos obtidos para as variáveis de crescimento de plantas anteriormente discutidas e corroboram com os encontrados em trabalhos realizados com arroz (Melo et al., 2006b; Mielezrski et al., 2008) e soja (Kolchinski et al., 2006). No trabalho de Höfs et al. (2004), desenvolvidos para o estudo dos efeitos do vigor das sementes sobre a área foliar, também foi constatado o mesmo efeito. Para a cultura de milho, Pommel et al. (2002) encontraram resultados semelhantes quanto a área foliar, acrescentando que as plantas de emergência tardia, obtiveram menores áreas foliares perante as plantas emersas previamente. 


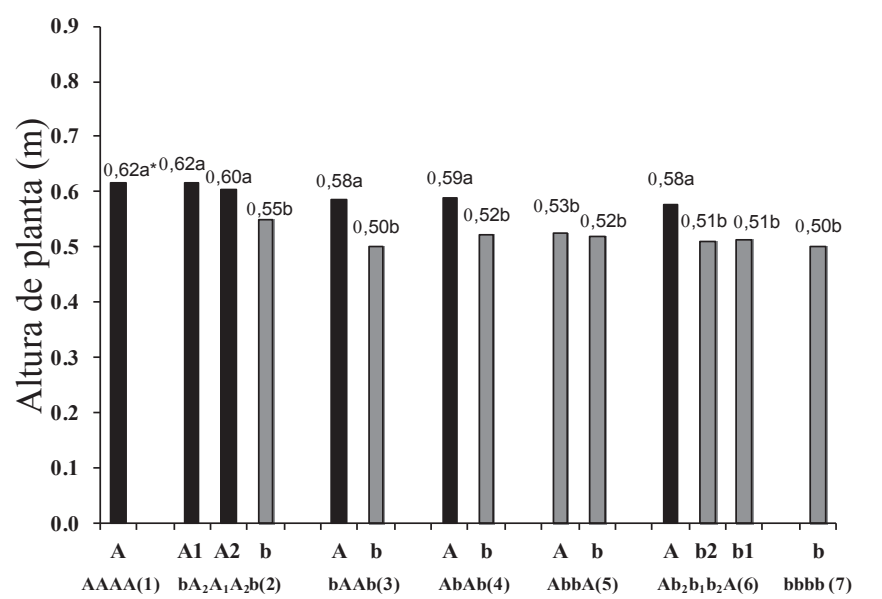

(A)

Distribuição de plantas
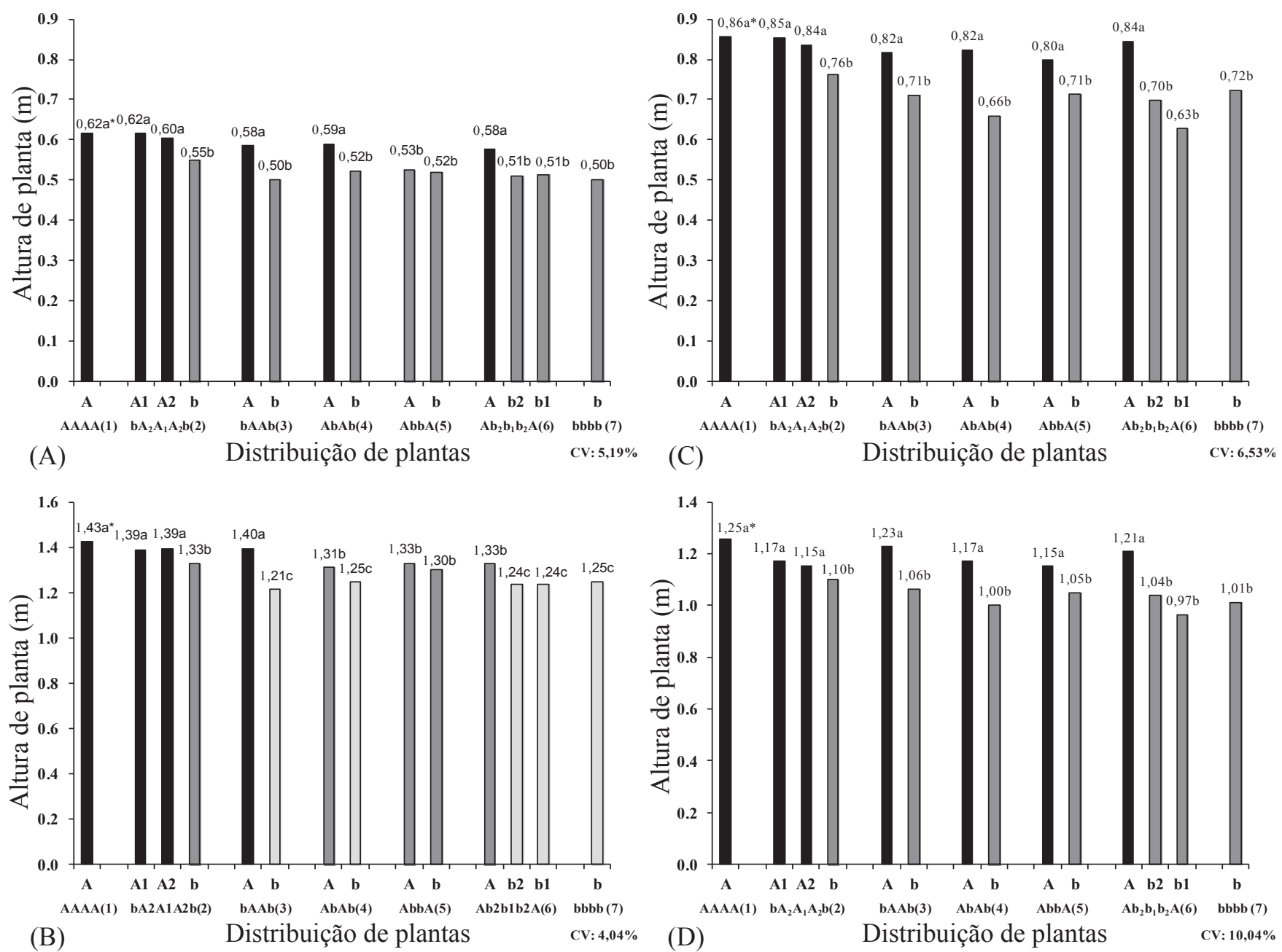

Figura 1. Altura (m) individual de plantas de milho dentro das populações constituídas pelas diferentes distribuições de plantas originadas de sementes de alto vigor ou de baixo vigor nos estádios de quatro (A, $1^{\circ}$ ano e $\mathrm{C}, 2^{\circ}$ ano) e oito (B, $1^{\circ}$ ano e $\mathrm{D}, 2^{\circ}$ ano) folhas.

A: plantas originadas de sementes de alto vigor; b: plantas originadas de sementes de baixo vigor; $\mathrm{A}_{1}$ e $\mathrm{b}_{1}$ : plantas localizadas, dentro do arranjo de plantas, entre duas plantas originadas de sementes de alto vigor ou duas plantas originadas de sementes de baixo vigor, respectivamente; $A_{2}$ e $b_{2}$ : plantas localizadas, dentro do arranjo de plantas, entre uma planta originada de semente de alto vigor e uma originada de semente de baixo vigor.*Médias seguidas por letras iguais não diferem entre si pelo teste Scott-Knott, com 5\% de significância. CV: coeficiente de variação.

Conforme observado com os resultados de crescimento inicial de plantas, as plantas originadas de sementes de baixo vigor apresentaram menor crescimento de parte aérea, porém a medida que os estádios de desenvolvimento se sucederam, essa influência do vigor sobre o crescimento das plantas tendeu a ser reduzido, tornando o desempenho da planta mais dependente das relações genótipo e ambiente. Realmente, quando não há redução significativa no estande inicial, não é esperada influência do potencial fisiológico das sementes sobre a produtividade final, para as plantas produtoras de grãos, no entanto, na competição por recursos dentro das populações de plantas (cultura), o rápido crescimento da parte aérea e sistema radicular serão decisivos para o futuro do indivíduo, pois é durante a fase de crescimento que se manifestam as características de plasticidade fenotípica e, sobretudo, as ações modificativas em relação às condições do habitat (Larcher, 2000). Ainda, a variabilidade de crescimento inicial das plantas nas 
parcelas semeadas com lotes heterogêneos pode intensificar a competição intra-específica dentro da população de plantas. Segundo Weiner (1990), as plantas de menor crescimento terão suas folhas em nível abaixo àquelas de plantas com maior crescimento, onde haverá menor penetração de radiação solar e a competição passará a ser desigual. Ainda, Pommel et al. (2002), confirmaram que a desuniformidade de emergência de plântulas resulta em diferenciação de interceptação de luz em plantas individuais.

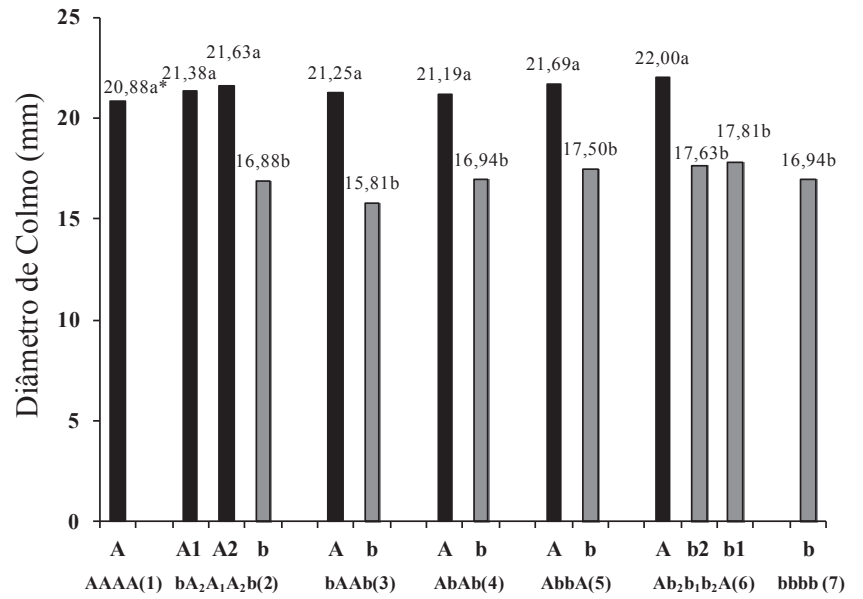

(A)

Distribuição de plantas

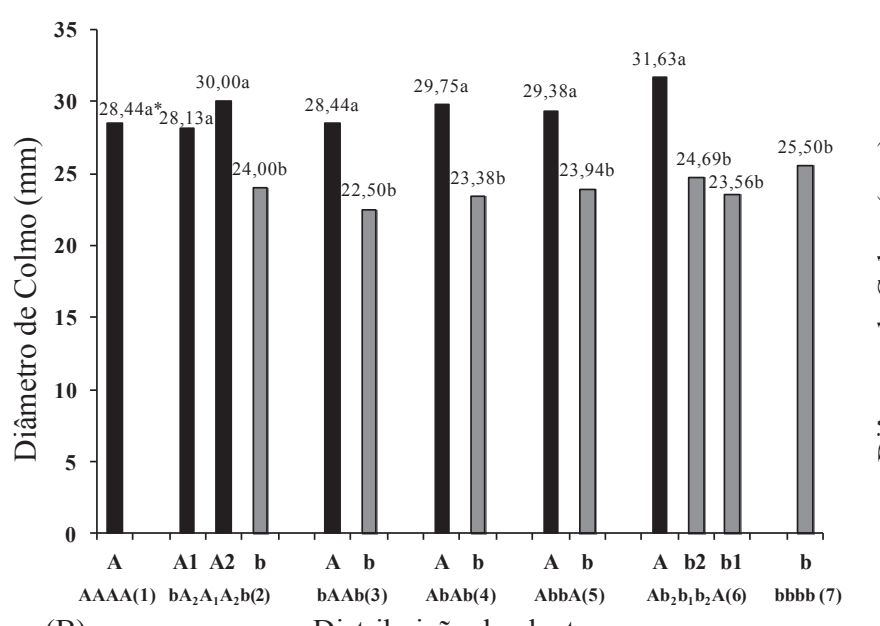

(B)
Distribuição de plantas
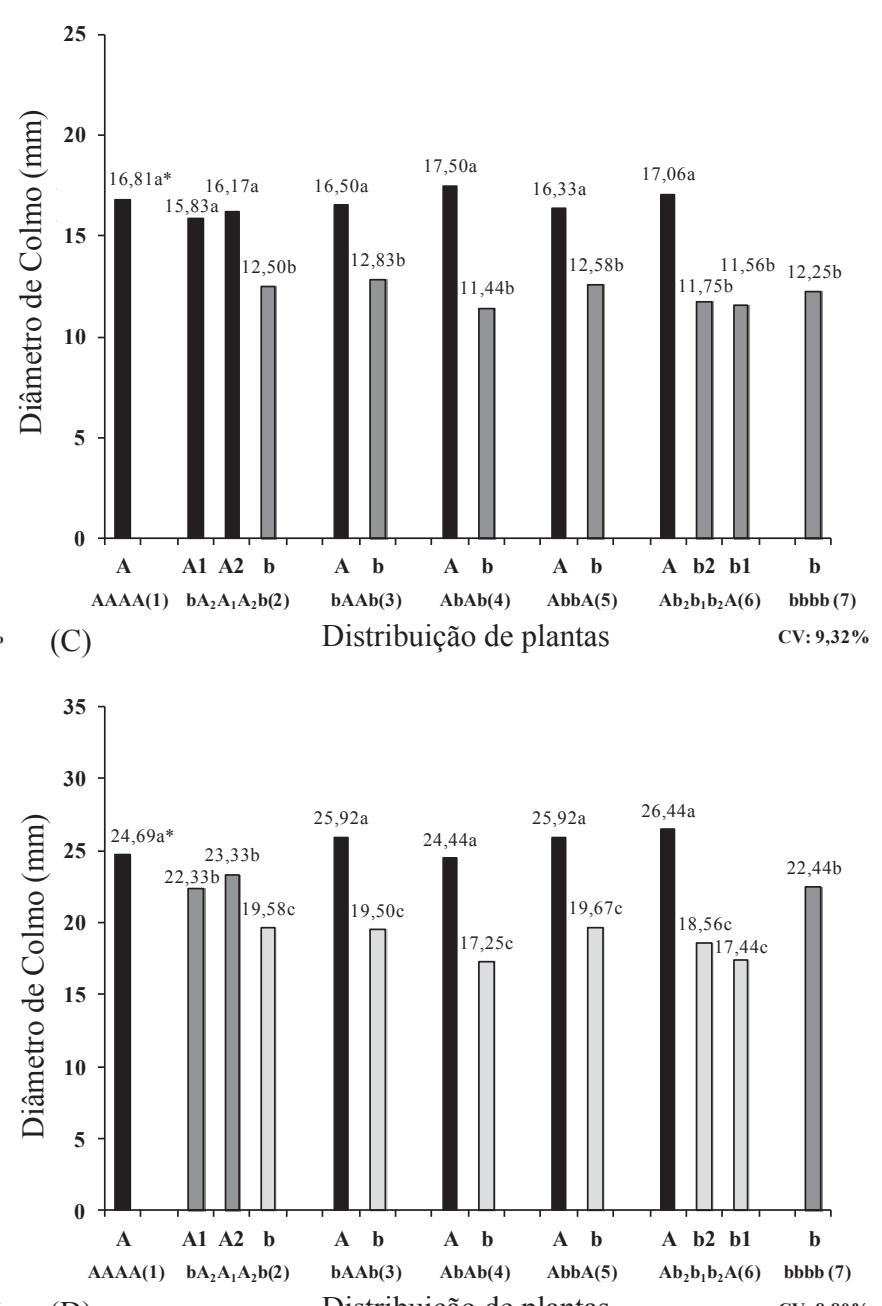

(D)

Figura 2. Diâmetro individual de colmo $(\mathrm{mm})$ de plantas de milho dentro das populações constituídas pelas diferentes distribuições de plantas originadas de sementes de alto vigor ou de baixo vigor, nos estádios de quatro (A, $1^{\circ}$ ano e $\mathrm{C}, 2^{\circ}$ ano) e oito (B, $1^{\mathrm{o}}$ ano e $\mathrm{D}, 2^{\circ}$ ano) folhas.

A: plantas originadas de sementes de alto vigor; $b$ : plantas originadas de sementes de baixo vigor; $A_{1}$ e $b_{1}$ : plantas localizadas, dentro do arranjo de plantas, entre duas plantas originadas de sementes de alto vigor ou duas plantas originadas de sementes de baixo vigor, respectivamente; $A_{2}$ e $b_{2}:$ plantas localizadas, dentro do arranjo de plantas, entre uma planta originada de semente de alto vigor e uma originada de semente de baixo vigor.*Médias seguidas por letras iguais não diferem entre si pelo teste Scott-Knott, com 5\% de significância. CV: coeficiente de variação.

Assim, como independentemente da distribuição, não foram constatadas diferenças de crescimento inicial entre plantas provenientes de sementes de alto vigor ou entre plantas provenientes de sementes de baixo vigor, pôde-se inferir que não houve efeito dominante entre plantas até o estádio fenológico de oito folhas; entretanto, 
a variabilidade existente entre as plantas dentro das distribuições semeadas com lotes heterogêneos revela a existência de plantas com capacidade competitiva diferente (Edmeades e Daynard, 1979).

Observou-se, também, que a menor disponibilidade de água durante o $2^{\circ}$ ano proporcionou competição intra-específica maximizada, justificando os resultados mais expressivos nas avaliações comparados ao $1^{\circ}$ ano, caracterizado como condição de competição intra-específica minimizada por ter sido conduzido de forma irrigada.
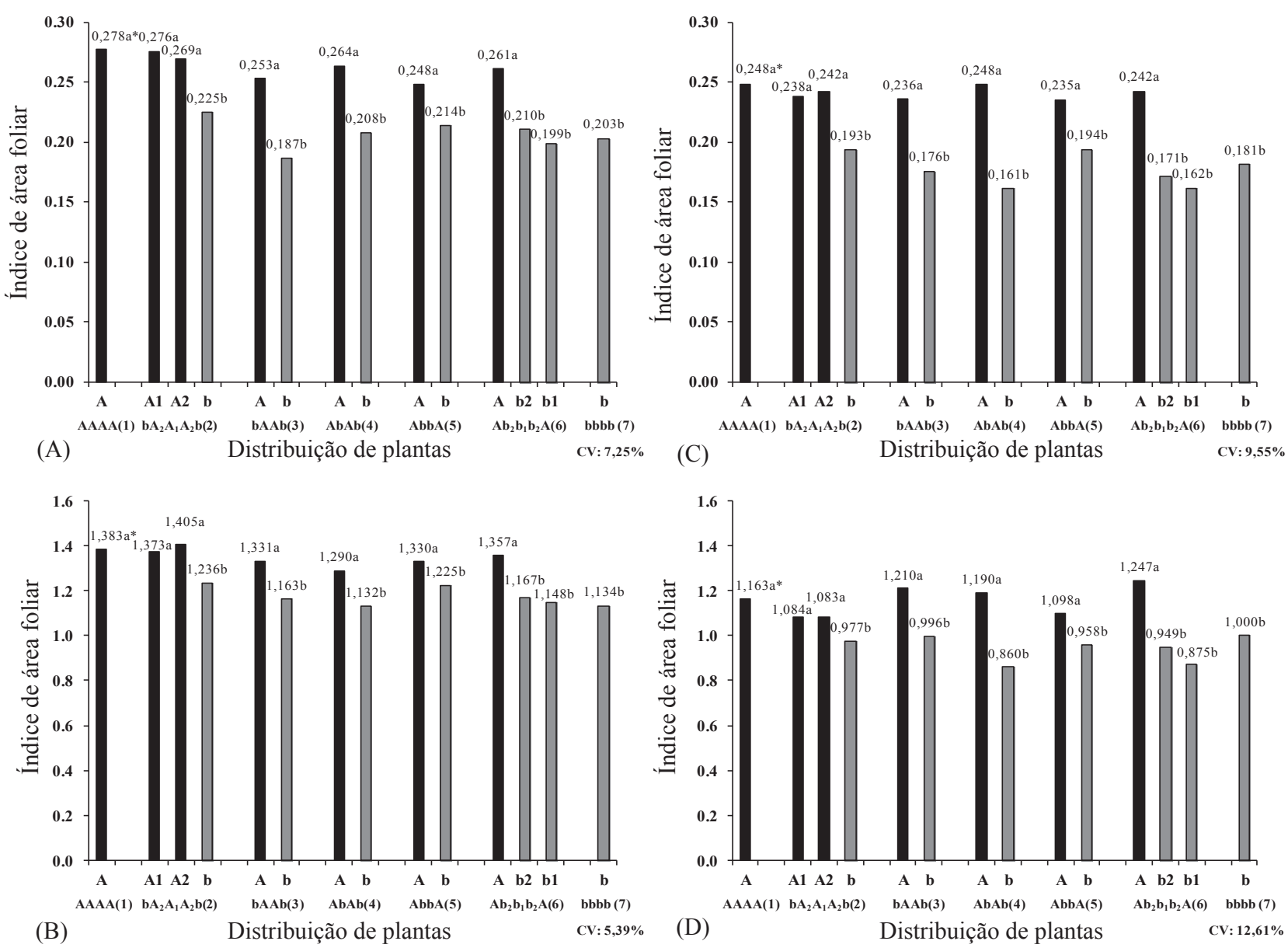

Figura 3. Índice individual de área foliar de plantas de milho dentro das populações constituídas pelas diferentes distribuições de plantas originadas de sementes de alto vigor ou de baixo vigor, nos estádios de quatro (A, $1^{\circ}$ ano e C, $2^{\circ}$ ano) e oito (B, $1^{\circ}$ ano e $\mathrm{D}, 2^{\circ}$ ano) folhas.

A: plantas originadas de sementes de alto vigor; $b$ : plantas originadas de sementes de baixo vigor; $A_{1}$ e $b_{1}$ : plantas localizadas, dentro do arranjo de plantas, entre duas plantas originadas de sementes de alto vigor ou duas plantas originadas de sementes de baixo vigor, respectivamente; $\mathrm{A}_{2} \mathrm{e} \mathrm{b}_{2}$ : plantas localizadas, dentro do arranjo de plantas, entre uma planta originada de semente de alto vigor e uma originada de semente de baixo vigor*Médias seguidas por letras iguais não diferem entre si pelo teste Scott-Knott, com 5\% de significância. CV: coeficiente de variação.

\section{Produtividade}

Em relação ao acúmulo de massa de matéria seca por planta (Figura 4A e 4B), de forma geral, a superioridade de crescimento inicial de plantas provenientes de sementes de alto vigor se mantiveram. Com os resultados para o $1^{\circ}$ ano
(Figura 4A), observou-se a superioridade dessas plantas sobre as provenientes de sementes de baixo vigor, em todas as distribuições de sementes. No $2^{\circ}$ ano (Figura 4B), com exceção para distribuição com $100 \%$ de sementes de baixo vigor (distribuição sete), os resultados do $1^{\circ}$ ano foram 
confirmados. Essa superioridade de acúmulo de massa de matéria seca de parte aérea condiz com os encontrados em trabalhos realizados com arroz (Melo et al., 2006b), milho (Pommel et al., 2002) e soja (Kolchinski et al., 2006).
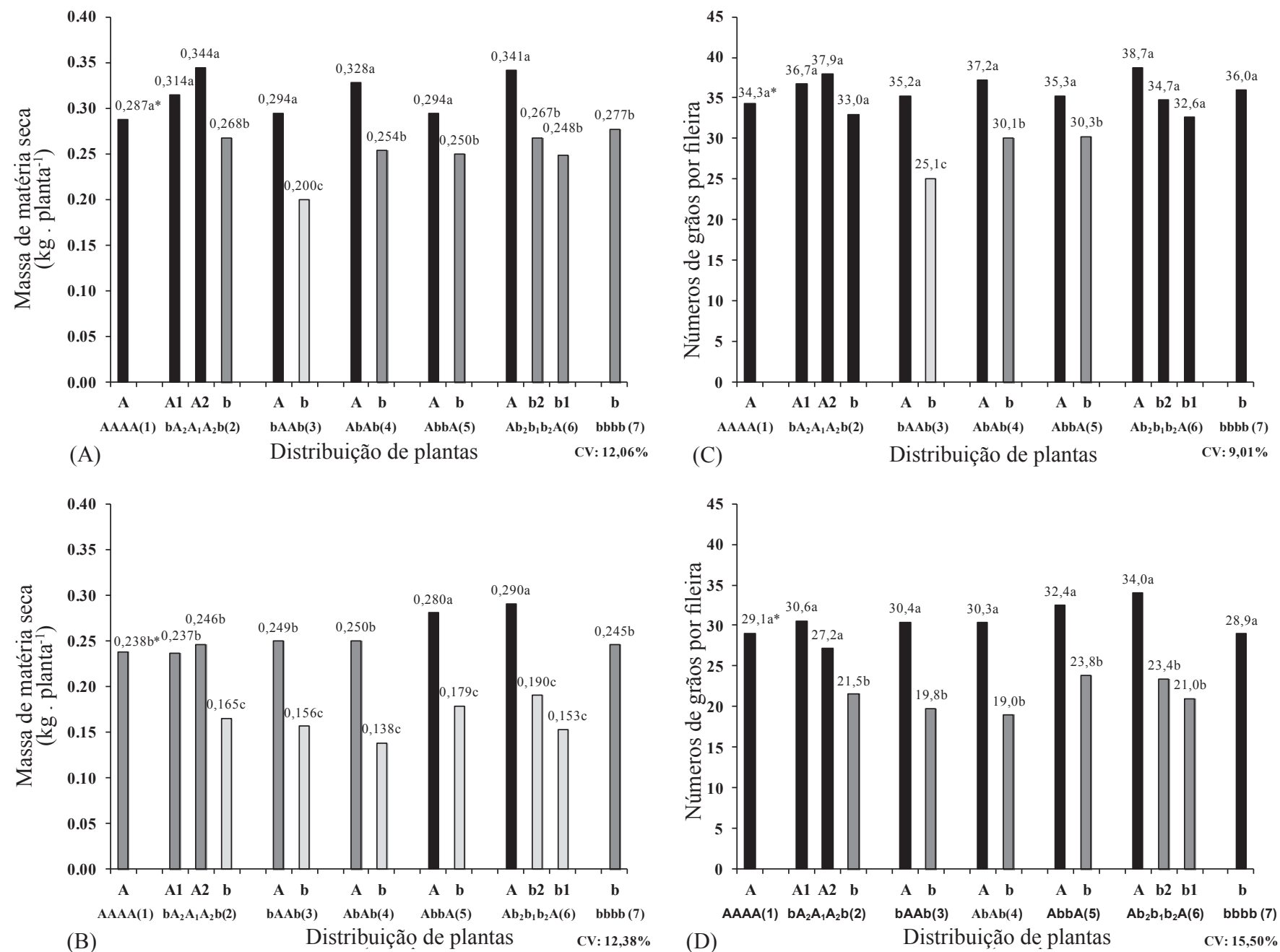

Figura 4. Massa de matéria seca de parte aérea $(\mathrm{kg})$ de plantas de milho (A, $1^{\circ}$ ano e $\mathrm{B}, 2^{\circ}$ ano) e número de grãos por fileira $\left(\mathrm{C}, 1^{\circ}\right.$ ano e $\mathrm{D}, 2^{\circ}$ ano) dentro das populações constituídas pelas diferentes distribuições de plantas originadas de sementes de alto vigor ou de baixo vigor.

A: plantas originadas de sementes de alto vigor; b: plantas originadas de sementes de baixo vigor; $\mathrm{A}_{1}$ e $\mathrm{b}_{1}$ : plantas localizadas, dentro do arranjo de plantas, entre duas plantas originadas de sementes de alto vigor ou duas plantas originadas de sementes de baixo vigor, respectivamente; $\mathrm{A}_{2}$ e $\mathrm{b}_{2}$ : plantas localizadas, dentro do arranjo de plantas, entre uma planta originada de semente de alto vigor e uma originada de semente de baixo vigor*Médias seguidas por letras iguais não diferem entre si pelo teste Scott-Knott, com 5\% de significância. CV: coeficiente de variação.

De acordo com Höfs et al. (2004), as plantas originadas de sementes de alto potencial fisiológico apresentam maior eficiência na produção de biomassa seca, sendo as diferenças reduzidas com o desenvolvimento das plantas, mas ainda mensuráveis ao final do ciclo da cultura. Tais resultados são condizentes com os encontrados neste trabalho. Ainda, em trabalho realizado por Almeida e Mundstock (2001b), estudando o efeito da desuniformidade da profundidade de semeadura em sementes de aveia, concluiu-se que a competição intra-específica resultante da emergência desuniforme de plântulas afetou a alocação de massa de matéria seca nas mesmas. Esse efeito pode ser comparado à 
utilização de sementes de diferentes níveis de vigor na linha de semeadura e que resultou desde o início do crescimento das plantas até a colheita, diferenças de crescimento entre plantas provenientes de sementes de alto vigor e provenientes de sementes de baixo vigor. Segundo Maddonni e Otegui (2004), para plantas maiores há o aumento da capacidade competitiva e podem ser identificadas como plantas dominantes na população de plantas, em contraste àquelas com menor capacidade competitiva para captura de recursos, sendas as plantas dominadas.

Quando estudadas as variáveis componentes de produção de grãos, representada pelo número de grãos por fileira, número de fileiras por espiga, massa de mil grãos e a produtividade final de grãos por planta, foi possível entender a influência de cada uma dessas variáveis sobre a produtividade de grãos.

Para número de grãos por espiga, no $1^{\circ}$ ano (Figura $4 \mathrm{C}$ ), diferenças entre plantas provenientes de sementes de alto vigor das provenientes de sementes de baixo vigor foram constatadas apenas nas distribuições três, quatro e cinco. Entretanto, no $2^{\circ}$ ano (Figura 4D), devido provavelmente a condição de competição intra-específica maximizada, as plantas provenientes de sementes de baixo vigor foram inferiores às plantas provenientes de sementes de alto vigor em combinações heterogêneas quanto ao nível de vigor das sementes, ou seja, distribuições dois, três, quatro, cinco e seis, assim como encontrado para acúmulo de massa de matéria seca.

Quanto ao número de fileiras por espiga, não foram constatadas diferenças entre os diferentes tipos de plantas, independentemente da distribuição e do ano experimental, (dados não apresentados), demonstrando que para esse fator não houve influência do vigor das sementes e, consequentemente, da competição intra-específica de plantas. Por meio desses resultados, foi possível inferir que até o estádio fenológico de oito folhas a competição intraespecífica não foi acentuada, visto que é nesse momento que o número de fileiras por espiga é definido (Magalhães et al., 2002). Isso corrobora com os resultados encontrados no crescimento inicial de plantas onde ainda puderam ser encontradas diferenças até mesmo nas distribuições homogêneas, um e sete, onde houve o desenvolvimento uniforme da população de plantas.

Com a avaliação da variável massa de mil grãos, foi possível identificar melhores resultados para as plantas provenientes de sementes de alto vigor nas distribuições dois, quatro e seis, apenas no $1^{\circ}$ ano (Figura 5A). No $2^{\circ}$ ano (Figura 5B), não houve diferenças entre tratamentos.
Salienta-se que a definição da densidade dos grãos ocorre no estádio fenológico de grãos leitosos (Fancelli e DouradoNeto, 2000; Magalhães et al., 2002), momento o qual, no $2^{\circ}$ ano, coincidiu com período de aproximadamente 20 dias sem ocorrência de chuvas. Como a eficiência da translocação de fotoassimilados para os órgãos produtivos é dependente da disponibilidade de água (Magalhães et al., 1998), esse fator provavelmente influenciou a não ocorrência de diferenças entre os tratamentos nesse ano.

Para a variável produtividade de grãos por planta (Figuras 5C e 5D), os resultados encontrados foram condizentes com os obtidos em outras variáveis de componentes de produção analisadas, principalmente acúmulo de massa de matéria seca e número de grãos por fileira.

Assim, no $1^{\circ}$ ano (Figura 5C) as plantas provenientes de sementes de alto vigor foram superiores às provenientes de sementes de baixo vigor nas distribuições heterogêneas quanto ao nível de vigor das sementes, com exceção para a distribuição dois, o que se refletiu de forma mais acentuada no $2^{\circ}$ ano (Figura 5D), onde para esses tratamentos, todas as plantas provenientes de sementes de baixo vigor foram inferiores em produtividade de grãos em relação às plantas provenientes de sementes de alto vigor.

Em geral para os componentes de produção, no $2^{\circ}$ ano do experimento, as plantas dos tratamentos com distribuição homogênea, um e sete, independentemente do nível de vigor das sementes, apresentaram desempenho semelhante, demonstrando que apesar do crescimento inicial diferenciado, em função do vigor das sementes, o crescimento uniforme da população minimizou os efeitos de competição intra-específica e nessa situação, o efeito do vigor das sementes passou a ser menos evidente com a sucessão das fases de desenvolvimento da cultura, não sendo mais constatados no final do ciclo. Assim, a homogeneidade do lote de sementes quanto ao nível de vigor, seja este alto ou mais baixo, mostra-se fundamental para a obtenção de altas produtividades em campos de produção de milho, prevenindo a ocorrência de plantas dominadas, as quais apresentarão níveis de produtividade inferiores.

Vale ressaltar que, nos dois anos avaliados, as plantas provenientes de sementes de baixo vigor das distribuições heterogêneas foram inferiores as plantas provenientes de sementes de baixo vigor da distribuição homogênea com sementes de baixo vigor $(100 \%$ de plantas provenientes de sementes de baixo vigor) quanto ao acúmulo de massa de matéria seca da parte aérea, número de grãos por fileira e produtividade de grãos. Isso indicou que a competição 
intra-específica acentuada pela desuniformidade de desenvolvimento das plantas nas distribuições heterogêneas quanto ao nível de vigor das sementes, resultou na ocorrência de plantas dominadas de milho, nesse caso plantas provenientes de sementes de baixo vigor. De forma oposta, as plantas provenientes de sementes de alto vigor de distribuições heterogêneas não foram superiores às plantas provenientes de sementes de alto vigor da distribuição homogênea com sementes de alto vigor $(100 \%$ de plantas provenientes de sementes de alto vigor), resultado esperado, visto que, a planta de milho exibe crescimento com baixa plasticidade, o que decorre, principalmente, pela baixa ocorrência de perfilhamento e ramificações laterais (Balbinot-Júnior e Fleck, 2005), não traduzindo em maior crescimento de plantas e produtividade de grãos a maior capacidade de competição por recursos.
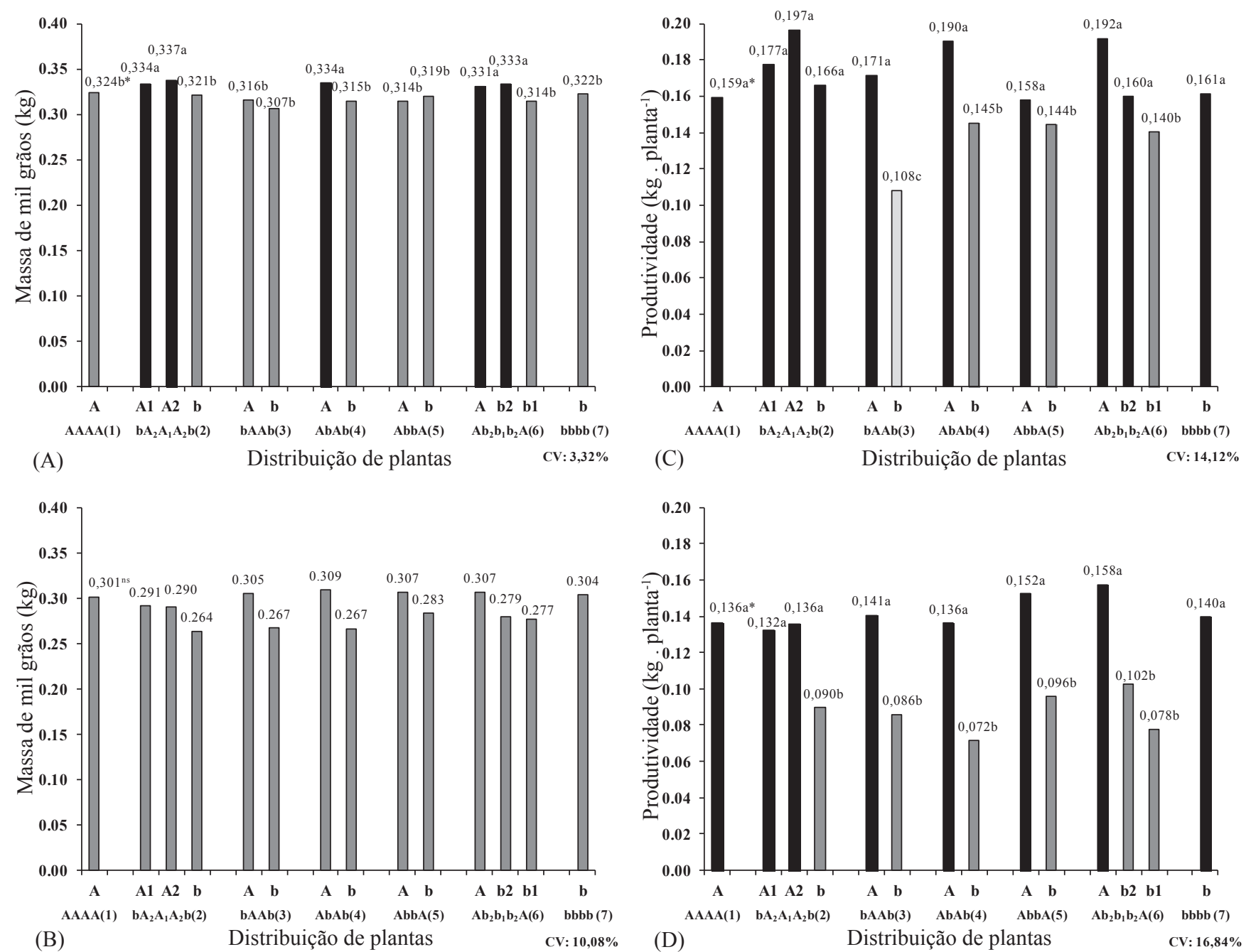

Figura 5. Massa de mil grãos (A, $1^{\circ}$ ano e B, $2^{\circ}$ ano) e produção de grãos por planta $\left(\mathrm{C}, 1^{\circ}\right.$ ano e $\mathrm{D}, 2^{\circ}$ ano $)$ dentro das populações constituídas pelas diferentes distribuições de plantas originadas de sementes de alto vigor ou de baixo vigor.

A: plantas originadas de sementes de alto vigor; b: plantas originadas de sementes de baixo vigor; $A_{1}$ e $b_{1}$ : plantas localizadas, dentro do arranjo de plantas, entre duas plantas originadas de sementes de alto vigor ou duas plantas originadas de sementes de baixo vigor, respectivamente; $A_{2}$ e $b_{2}$ : plantas localizadas, dentro do arranjo de plantas, entre uma planta originada de semente de alto vigor e uma originada de semente de baixo vigor*Médias

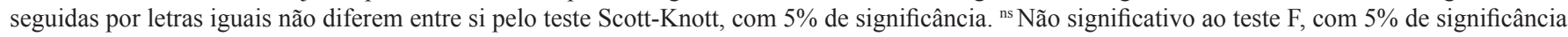
CV: coeficiente de variação. 
Pommel et al. (2002), estudando a competição intraespecífica na cultura de milho, verificaram, também, que as plantas dominadas apresentaram menor produtividade de grãos. Segundo os mesmos autores, a variável número de grãos por espiga foi onde se observaram diferenças mais evidentes, resultados condizentes aos encontrados para número de grãos por fileira no presente trabalho. Tais resultados, corroboram com os obtidos para número de grãos e produtividade de grãos por planta em trabalhos com a cultura de milho realizados por Andrade et al. (1999), Vega et al. (2001b), Kiniry et al. (2002) e Maddonni e Otegui $(2004 ; 2006)$ e evidenciaram os efeitos diferenciados da competição intra-específica no crescimento de plantas e alocação de biomassa nas estruturas produtivas (Vega et al. 2001a; Echarte e Andrade, 2003).

Dessa forma, pode-se inferir que o número de grãos por fileira foi a variável dos componentes de produção que mais influenciou os resultados de produtividade final de grãos por planta. Além disso, quando houve competição intra-específica mais acentuada, no $2^{\circ}$ ano experimental, os efeitos do vigor das sementes sobre o desempenho das plantas foram evidenciados.

Com esses resultados foi possível identificar a influência do vigor das sementes sobre o crescimento inicial de plantas e quando existe grande variabilidade de crescimento, ocorre a intensificação da competição intra-específica, resultando na diminuição da capacidade competitiva em relação àquelas de emergência tardia, refletindo negativamente em produtividade.

\section{Conclusões}

$\mathrm{O}$ vigor de sementes está diretamente relacionado ao crescimento inicial das plantas de milho; porém, seus efeitos não persistem até o final do ciclo da cultura, quando há o uso de lotes de sementes constituídos apenas por sementes de alto vigor ou apenas por sementes de baixo vigor (lotes de sementes homogêneos quanto ao vigor das sementes).

O uso de lotes de sementes constituídos por sementes de alto vigor e de baixo vigor (lotes de sementes heterogêneos) resulta em maior competição intraespecífica proporcionando menor capacidade competitiva às plantas originadas de sementes de baixo vigor, sendo estas dominadas pelas originadas de sementes de alto vigor, refletindo negativamente em produção por planta.

\section{Referências}

ALMEIDA, M.L.; MUNDSTOCK, C.M. A qualidade da luz afeta o afilhamento em plantas de trigo, quando cultivadas sob competição. Ciência Rural, v.31, n.3, p.401-408, 2001a. http://www.scielo.br/scielo. php?script=sci_arttext\&pid=S0103-84782001000300006\&lng=en\&nrm=iso

ALMEIDA, M.L.; MUNDSTOCK, C.M. O afilhamento da aveia afetado pela qualidade da luz em plantas sob competição. Ciência Rural, v.31, n.3, p.393-400, 2001b. http://www.scielo.br/scielo.php?script=sci arttext\&pid=S0103-84782001000300005\&lng=en\&nrm=iso

ANDRADE, F.H.; VEJA, C.; UHART, S.; CIRILO, A.; CANTARERO, M.; VALENTINUS, O. Kernel number determination in maize. Crop Science, v.39, n.2, p.453-459, 1999. https://www.crops.org/publications/ cs/pdfs/39/2/CS0390020453

BALBINOT JUNIOR, A.A.; FLECK, N.G. Competitividade de dois genótipos de milho com plantas daninhas sob diferentes espaçamentos entre fileiras. Planta Daninha, v.23, n.3, p.415-421, 2005. http://www.scielo.br/scielo.php?script=sci_arttext\&pid=S0100$83582005000300004 \& \operatorname{lng}=$ en\&nrm $=$ iso

BRASIL. Ministério da Agricultura, Pecuária e Abastecimento. Regras para análise de sementes. Ministério da Agricultura, Pecuária e Abastecimento. Secretaria de Defesa Agropecuária. Brasília: MAPA/ ACS, 2009. 395p.

ECHARTE, L.; ANDRADE, F. Harvest index stability of Argentinean maize hybrids released between 1965 and 1993. Field Crops Research, v.82, n.1, p.1-12, 2003. http://pdn.sciencedirect.com/ science? ob=MiamiImageURL\&_cid $=271162 \&$ user $=1631782 \&$ pii $=$ S $0378429002002320 \&$ \& check=y\&_origin=search\& zone $=$ rslt_list_item $\&$ coverDate $=2003-03-20 \& w c h p=d G L b V 1 S-z S$ kWA \& md $5=689$ d 5 c 087 f 6268 c 62 c 47 b 0 f0 02 be $38674 / 1$ - s 2.0 S0378429002002320-main.pdf

EDMEADES, G.O.; DAYNARD, T.B. The development of plant-toplant variability in maize at different planting densities. Canadian Journal of Plant Sciences, v.59, n.3, p.561-576, 1979. http://pubs.aic.ca/ doi/pdf/10.4141/cjps79-095

EMPRESA BRASILEIRA DE PESQUISA AGROPECUÁRIA EMBRAPA. Sistema Brasileiro de Classificação de Solos. 2.ed. Brasília, DF: Embrapa Informações Tecnológicas; Rio de Janeiro:Embrapa Solos, 2006. 306p.

FANCELLI, A.L.; DOURADO-NETO, D. Produção de milho. Guaíba: Agropecuária, 2000. 360p.

FESSEL, S.A.; RODRIGUES, T.J.D.; FAGIOLI, M.; VIERIA, R.D Temperatura e período de exposição no teste de envelhecimento acelerado em sementes de milho. Revista Brasileira de Sementes, v.22, n.2, p.163-170, 2000. http://www.abrates.org.br/revista/artigos/2000/ v22n2/artigo 22.pdf 
HARPER, J.L. Population biology of plants. New York: Academic Press, 1977. 892p.

HÖFS, A.; SCHUCH, L.O.B.; PESKE, S.T.; BARROS, A.C.S.A. Emergência e crescimento de plântulas de arroz em resposta à qualidade fisiológica de sementes. Revista Brasileira de Sementes, v.26, n.1, p.92-97, 2004. http://www.scielo.br/pdf/\%0D/rbs/v26n1/a14v26n1.pdf

KINIRY, J.R.; XIE, Y.; GERIK, T.J. Similarity of maize seed number responses for a diverse set of sites. Agronomie, v.22, n.3, p.265-272, 2002. http://www.ars. usda.gov/SP2UserFiles/Place/62060000/almanac/SimilarityofMaizeSeed.pdf

KOLCHINSKI, E.M.; SCHUCH, L.O.B.; PESKE, S.T. Vigor de sementes e competição intra-específica em soja. Ciência Rural, v.35, n.6, p.1248-1256, 2005. http://www.scielo.br/scielo.php?script=sci_ arttext\&pid=S0103-84782005000600004\&lng=en\&nrm=iso

KOLCHINSKI, E.M.; SCHUCH, L.O.B.; PESKE, S.T. Crescimento de soja em função do vigor das sementes. Revista Brasileira de Agrociência, v.12, n.2, p.163-166, 2006. http://www.ufpel.tche.br/faem/agrociencia/ v12n2/artigo07.htm

LARCHER, W. Ecofisiologia vegetal. São Carlos: Rima Artes e Textos, 2000. 531p.

MADDONNI, G.A.; OTEGUI, M.E. Intra-specific competition in maize: early establishment of hierarchies among plants affects final kernel set. Field Crops Research, v.85, n.1, p.1-13, 2004. http://www.sciencedirect. com/science/article/pii/S0378429003001047

MADDONNI, G.A.; OTEGUI, M.E. Intra-specific competition in maize: contribution of extreme plant hierarchies to grain yield, grain yield components and kernel composition. Field Crops Research, v.97, n.2/3, p.155-166, 2006. http://www.sciencedirect.com/science/article/pii/ S0378429005002388

MAGALHÃES, P.C.; DURÃES, F.O.M.; OLIVEIRA, A.C. de. Efeitos do quebramento do colmo no rendimento de grãos de milho. Ciência e Agrotecnologia, v.22, n.3, p.279-289, 1998. http://www.alice.cnptia. embrapa.br/bitstream/doc/482390/1/Efeitosquebramento.pdf

MAGALHÃES, P.C.; DURÃES, F.O.M.; CARNEIRO,N.P.; PAIVA, E. Fisiologia do milho. Sete Lagoas: EMBRAPA-CNPMS, 2002. 23p. (Embrapa - CNPMS. Circular Técnica 22,).

MAGUIRE, J.D. Speed of germination aid in selection and evaluation for seedling emergence and vigor. Crop Science, v.2, n.2, p.176-77, 1962. https://www.crops.org/publications/cs/abstracts/2/2/CS0020020176

MARCOS-FILHO, J. Fisiologia de sementes de plantas cultivadas. Piracicaba: FEALQ, 2005. 495p.

MELO, P.C.S.; ANUNCIAÇÃO FILHO, C.J.; OLIVEIRA, F.J.; BASTOS, G.Q.; TABOSA, J.N.; SANTOS, V.F.; MELO, M.R.C.S. Seleção de genótipos de arroz tolerantes à salinidade durante a fase vegetativa. Ciência Rural, v.36, n.1, p.58-64, 2006a. http://www.scielo. br/pdf/cr/v36n1/a09v36n1.pdf
MELO, P.T.B.S.; SCHUCH, L.O.B.; ASSIS, F.N.; CONCENÇO, G. Comportamento individual de plantas originadas de sementes com diferentes níveis de qualidade fisiológica em populações de arroz irrigado. Revista Brasileira de Sementes, v.28, n.2, p.84-94, 2006 b. http://www.scielo.br/pdf/rbs/v28n2/a11v28n2.pdf

MEROTTO-JÚNIOR, A.; SANGOI, L.; ENDER, M.; GUIDOLIN, A.F.; HAVERROTH, H.S. A desuniformidade de emergência reduz o rendimento de grãos de milho. Ciência Rural, v.29, n.4, p.595-601, 1999. http://www.scielo.br/pdf/cr/v29n4/a04v29n4.pdf

MIELEZRSKI, F.; SCHUCH, L.O.B.; PESKE, S.T.; PANOZZO, L.E.; PESKE, F.B.; CARVALHO, R.R. Desempenho individual e de populações de plantas de arroz híbrido em função da qualidade fisiológica das sementes. Revista Brasileira de Sementes, v.30, n.3, p.86-94, 2008. http://www.scielo.br/pdf/rbs/v30n3/18.pdf

MONDO, V.H.V.; CICERO, S.M. Análise de imagens na avaliação da qualidade de sementes de milho localizadas em diferentes posições na espiga. Revista Brasileira de Sementes, v.27, n.1, p.9-18, 2005. http://www.scielo.br/scielo.php?pid=S0101$31222005000100002 \&$ script $=$ sci_arttext

MONTGOMERY, E.G. Correlation studies in corn. Nebraska Agricultural Experiment Station Annual Report, v.24, p.108-159, 1911.

POMMEL, B.; MOURAUX, D.; CAPPELLEN, O.; LEDENT, J.F. Influence of delayed emergence and canopy skips on the growth and development of maize plants: a plant scale approach with CERES-Maize. European Journal of Agronomy, v.16, p.263-277, 2002. http://www. sciencedirect.com/science/article/pii/S1161030101001307

SCHUCH, L.O.B.; NEDEL, J.L.; ASSIS, F.N.; MAIA, M.S. Vigor de sementes e análise de crescimento de aveia preta. Scientia Agricola, v.57, n.2, p.305-312, 2000. http://www.scielo.br/scielo.php?pid=S010390162000000200018\&script=sci_arttext

SCOTT, A.J.; KNOTT, M. A Cluster Analysis Method for Grouping Means in the Analysis of Variance. Biometrics, v.30, n.3, p.507-512, 1974. http://www.ime.usp.br/ abe/lista/pdfXz71qDkDx1.pdf

SILVA, P.R.F.; ARGENTA, G.; REZERA, F. Resposta de híbridos de milho irrigado à densidade de plantas em três épocas de semeadura. Pesquisa Agropecuária Brasileira, v.34, n.4, p.585-592, 1999. http://www.scielo.br/scielo.php?script=sci_arttext\&pid=S0100204X1999000400009

TEKRONY, D.M.; EGLI, D.B.; WICKHAM, D.A. Corn seed vigor effect on no-tillage field performance: II. Plant growth and grain yield. Crop Science, v.29, p.1528-1531, 1989. https://www.crops.org/publications/cs/pdfs/29/6/ CS0290061528

VEGA, C.R.C.; ANDRADE, F.H.; SADRAS, V.O. Reproductive partitioning and seed set efficiency in soybean, sunflower and maize. Field Crops Research, v.72, p.163-175, 2001a. http://www.sciencedirect. com/science/article/pii/S0378429001001721 
VEGA, C.R.C.; ANDRADE, F.H.; SADRAS, V.O.; UHART, S.A.; VALENTINUZ, O.R. Seed number as a function of growth: a comparative study in soybean, sunflower, and maize. Crop Science, v.41, p.748-754, 2001b. https://www.crops.org/publications/cs/pdfs/41/3/748

VILLIERS, T.A. Ageing and longevity of seeds in field conditions. In: HEYDECKER, W. (Ed.). Seed ecology. London: The Pennsylvania State University Press, p.265-288, 1973.
WEINER, J. Asymmetric competition in plant populations. Trends in Ecology \& Evolution, v.5, n.11, p.360-364, 1990. http://www. jacobweiner.dk/Site/Publications_files/Weiner_1990.pdf 